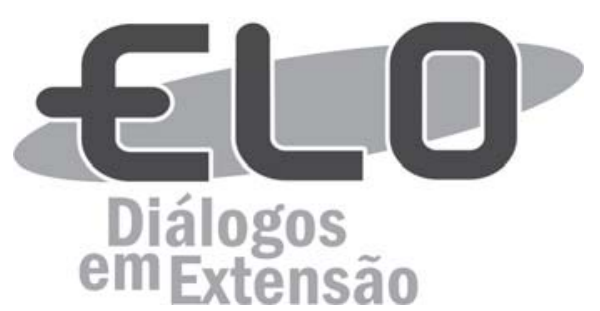

\title{
Análise da articulação do Projeto Pré-Enem Comunitário da Universidade Federal de Alagoas com as Politicas de Inclusão Social
}

\author{
Ana Paula Nascimento dos Santos ${ }^{1}$, Juliana Maria Silva Pereira², \\ Angélica de Lucena Nóbrega ${ }^{3}$, Luciana Peixoto Santa Rita e Ibsen Mateus Bittencourt $^{5}$
}

\begin{abstract}
Resumo: O artigo analisa a articulação do Projeto Pré-Enem Comunitário da Universidade Federal de Alagoas com as Políticas de Inclusão Social, em particular a Política de Cotas e o Programa Universidade para Todos. Trata-se de pesquisa qualitativa, quanto ao método e à forma de abordar o problema. A investigação consiste no enquadramento do projeto aos três eixos integradores necessários à articulação contidos na Política Nacional de Extensão ao mesmo tempo em que estabelece correlações demonstrando a convergência de objetivos e finalidades entre o projeto e as politicas destacadas. Os resultados apontam para a adequação da ação aos referidos eixos e confirmam o apoio às politicas. Conclui-se que o estudo contribui para as discussões sobre a responsabilidade social das IFES, a necessidade de financiamento das ações de extensão e o fortalecimento do fazer extensionista.
\end{abstract}

Palavras-chave: Extensão Universitária. Políticas Públicas. Políticas de Inclusão Social. Pré-Enem Comunitário.

Área Temática: Educação.

\section{Analysis of the articulation of the Pre-Enem Community Project of the Federal University of Alagoas with the Policies of Social Inclusion}

\begin{abstract}
The article analyzes the articulation of the Pre-Enem Community Project of the Federal University of Alagoas with the Policies of Social Inclusion, in particular the Quotas Policy and the University for All Program. It is qualitative research, as to the method and the way of approaching the problem. The research consists of framing the project to the three integrating axes necessary for the articulation contained in the National Extension Policy, while establishing correlations demonstrating the convergence of objectives and purposes between the project and the highlighted policies. The results point to the adequacy of the action to these axes and confirm the support for the policies. It is concluded that the study contributes to the discussions on: the social responsibility of the IFES; the need to finance extension actions; and strengthening the extension worker.
\end{abstract}

Keywords: University Extension. Public policy. Social Inclusion Policies. Pre-Enem Community.

\section{Análisis de la articulación del Proyecto Pre-Enem Comunitario de la Universidad Federal de Alagoas con las Politicas de Inclusión Social}

Resumen: El artículo analiza la articulación del Proyecto Pre-Enem Comunitario de la Universidad Federal de Alagoas con las Políticas de Inclusión Social, en particular la Política de Cuotas y el Programa

\footnotetext{
${ }^{1}$ Discente do Programa de Mestrado Profissional em Administração Pública (PROFIAP) pela Universidade Federal de Alagoas/UFAL. Endereço: Av. Lourival Melo Mota, S/N, Tabuleiro do Martins, Maceió - AL, CEP: 57072-970. Telefone: (82) 988403729. E-mail: paulinha_nasci@hotmail.com

${ }^{2}$ Discente do PROFIAP/UFAL. E-mail: jumariasp@gmail.com

${ }^{3}$ Discente do PROFIAP/UFAL. E-mail: trezeana@hotmail.com

${ }^{4}$ Docente da Faculdade de Economia, Administração e Contabilidade/FEAC/UFAL e do PROFIAP. E-mail: 1santarita@hotmail.com

${ }^{5}$ Docente da FEAC/UFAL e do PROFIAP. E-mail: ibsen.ead@gmail.com
} 
Universidad para Todos. Se trata de una investigación cualitativa, en cuanto al método y la forma de abordar el problema. La investigación consiste en el encuadramiento del proyecto a los tres ejes integradores necesarios a la articulación contenidos en la Política Nacional de Extensión al mismo tiempo que establece correlaciones demostrando la convergencia de objetivos y finalidades entre el proyecto y las politicas destacadas. Los resultados apuntan a la adecuación de la acción a los referidos ejes y confirma el apoyo a las politicas. Se concluye que el estudio contribuye a las discusiones sobre: la responsabilidad social de las IFES; la necesidad de financiamiento de las acciones de extensión; y el fortalecimiento del hacer extensionista.

Palabras clave: Extensión Universitaria. Políticas públicas. Políticas de Inclusión Social. Pre-Enem Comunitario.

\section{Introdução}

As Instituições Federais de Ensino Superior - IFES, enquanto lócus do conhecimento, assumem papel relevante nos debates e na proposição de soluções relacionadas ao desenvolvimento humano e sustentável da sociedade. Essa visão se consolidou após a Constituição de 1988, no contexto de reabertura democrática, com a reafirmação do princípio da indissociabilidade entre ensino, pesquisa e extensão. O cenário requeria das IFES um maior diálogo com os diversos setores e uma formação acadêmica articulada e comprometida com as demandas sociais (GONÇALVES, 2016).

O diálogo entre universidade e sociedade tem como uma de suas finalidades a melhoria da qualidade da vida da população. Com base nessa afirmação, entende-se que a extensão, considerada "processo interdisciplinar, educativo, cultural, científico e político", atua como viabilizadora desse elo. Sem a concretização desse processo educativo, os propósitos da educação superior de qualidade correm o risco de não serem cumpridos em sua integralidade (FORPROEX, 2012).

As universidades coexistem com os diversos problemas sociais, a respeito dos quais os governos formulam políticas, no intuito de assegurar direitos, visando, em suma, o bem estar da sociedade. Nesse contexto, questões como a defesa das minorias, o combate a pobreza e a superação de desigualdades vêm ganhando cada vez mais espaço na agenda governamental, por estarem pautadas, primeiramente, pela Constituição Cidadã 1988 que se comprometeu com valores sociais imprescindíveis ao Estado Democrático de Direito. E em segundo, pelo "aumento da participação social nas decisões sobre elaboração, implementação e monitoramento das políticas públicas" (IPEA, 2012).

Destaca-se, nesse cenário, as Políticas de Inclusão Social e de acesso à Educação Superior que apresentam em seu escopo o intuito de contribuir para a diminuição das desigualdades econômicas e sociais existentes no país. Acredita-se que tais políticas promovem a democratização dos serviços oferecidos à população e, quando executadas, permitem uma maior variedade nas camadas sociais representadas na administração pública.

Não obstante aos avanços ocasionados por essas políticas, "o índice de oportunidades humanas ao acesso ao ensino superior no Brasil está muito longe da situação ideal que ocorre quando o acesso é universal e não há desigualdade de oportunidades no ingresso" (CARVALHO e WALTENBERG, 2015, p. 369). Considerando essa conjuntura, é importante frisar a necessidade dos diversos setores da sociedade participarem na busca de soluções e no auxílio às ações governamentais. Entre eles se encontram as IFES que, por meio de suas ações de extensão, podem oferecer ao poder público e a sociedade saídas para transpor realidades adversas.

Partindo desse entendimento e tomando como referência as ações de extensão comprometidas com o enfrentamento da exclusão, das vulnerabilidades sociais e do combate às desigualdades, o Projeto Pré-Enem Comunitário da Universidade de Alagoas, desde 2006, vem atuando no Estado mediante a formação de discentes de origem popular, possibilitando a construção de saberes e o ingresso ao Ensino Superior, adotando critérios que contemplam grupos populacionais caracterizados pela falta de oportunidades, semelhantemente às Políticas de Inclusão Social.

Com base nessa realidade, o presente artigo busca responder a seguinte questão: o Projeto PréEnem, por intermédio de sua atuação, auxilia as políticas de inclusão social, a exemplo da Política de Cotas e do Programa Universidade para Todos (PROUNI), possibilitando que pessoas advindas de camadas populares tenham maiores oportunidades de ingressar em Instituições de Ensino Superior (IES)? Norteado por essa indagação, o artigo objetiva analisar a articulação do Projeto Pré-Enem Comunitário com as Políticas citadas. Os objetivos específicos são: Descrever breve histórico do Projeto Pré-Enem; Verificar o enquadramento do projeto às orientações contidas na Política Nacional de 
Extensão no tocante ao apoio das ações de extensão às políticas públicas; Correlacionar objetivos e finalidades do Projeto com as políticas em questão.

Os motivos que impulsionaram a realização da pesquisa, somados aos já discutidos até aqui, fundamentam-se na Política Nacional de Extensão Universitária que, no conjunto de seus desafios, defende o fortalecimento da relação "autônoma e crítico-propositiva da Extensão com as políticas públicas por meio de programas estruturantes, capazes de gerar impacto social". Essa relação deve ser "orientada pelo compromisso com o enfrentamento da exclusão e vulnerabilidade sociais e combate a todas as formas de desigualdade e discriminação" (FORPROEX, 2012, p. 39 e 44).

Além disso, pretende-se dar visibilidade ao Pré-Enem Comunitário reconhecendo sua importância para Universidade e para a Sociedade. Tanto é assim que a reestruturação do programa Conexões de Saberes, do qual o projeto faz parte, compõe o conjunto de metas estabelecidas no Plano de Desenvolvimento Institucional (UFAL, 2013b). Seguindo a mesma linha de pensamento, defende-se que esse estudo de caso contribui para as discussões sobre a responsabilidade social das IFES, a necessidade de financiamento para realização mais efetiva dessas ações e para o aprimoramento e fortalecimento do fazer extensionista.

O artigo está estruturado da seguinte forma: a próxima seção aponta a revisão de literatura. Nela serão abordados os temas que serviram de base para o desenvolvimento da pesquisa. A seguir, registrase a metodologia. Logo depois, os resultados e discussão e, por fim, têm-se as considerações finais.

\section{Referencial Teórico}

\section{Políticas Públicas}

De acordo com Marta Arretche (2003), o interesse pela área de políticas públicas tem aumentado significativamente. Tal fato se revela pelo número de estudos a respeito da temática. Atribui-se a isso mudanças na conjuntura social, mediante a implementação de programas governamentais caracterizados pela inovação e experimentação, o acesso a cargos eletivos por segmentos habitualmente excluídos, bem como uma maior participação da população nas políticas setoriais demonstrando atenção sobre o funcionamento do Estado brasileiro.

Não há uma definição única sobre políticas públicas. Em revisão de literatura elaborada pela pesquisadora Celine Souza (2006), alguns conceitos, de diferentes autores, são discutidos, entre os quais o de que a política pública é a soma de atividades governamentais que agem diretamente ou através de delegação e que interferem na vida dos cidadãos (PETERS,1986). Em outras palavras, a ação dos governos, em atendimento às demandas sociais, é traduzida em "programas e ações que produzirão resultados ou mudanças no mundo real" (SOUZA, 2006, p.26).

Políticas Públicas podem ser entendidas a partir de uma tipologia que as enxerga como um ciclo deliberativo composto por etapas (SOUZA, 2006). Kington, citado por Capella (2006), sequencia esse processo a começar pela criação de uma agenda, em seguida pela apreciação de alternativas adequadas à formulação das políticas para, após isso, ocorrer a implementação. As duas primeiras fases se concentram em uma gama de questões advindas das demandas da sociedade e que são discutidas, priorizando-se, num primeiro momento, umas em detrimento de outras, devido à complexidade e à quantidade significativa desses assuntos.

A implementação ocorre com a materialização das propostas discutidas em etapas anteriores. Dalfior et al. (2015, p. 285) entende que esse momento contempla uma complexa rede de "atores que dão sustentação à política, formando 'elos de ligação' que sustentam os programas por meio da coordenação interinstitucional e da capacidade de mobilizar recursos institucionais", definindo essa etapa como um "processo de aprendizagem".

No entanto, para institucionalização das políticas públicas algumas variáveis devem ser consideradas, entre elas, a disponibilização de recursos financeiros. Lima e D'ascenzi (2013) tomando como referência Howlett e Ramesh (1995), Van Meter e Van Horn (1996) e Sabatier e Mazmanian (1996) relacionam os êxitos do processo de implementação e seu sucesso à questão do financiamento e ao contexto econômico.

A fase final do ciclo das políticas públicas é a avaliação. Esse momento caracteriza-se pela legitimação desse instrumento social e comprovação de seus efeitos. "Consiste na interrogação sobre o impacto da política” (LIMA E D’ASCENZI, 2014, p.51). Como defende Lima e Ramos (2014, p.67), 
nessa etapa "destacam-se os avanços e resultados alcançados e apresentam-se as restrições de recursos orçamentários e humanos, entre outras, que dificultaram a obtenção de melhores desempenhos".

Corroborando com as discussões nessa área, Bueno e Carloto (2015) ponderam que, nos últimos anos, a avaliação e o monitoramento das políticas públicas têm recebido atenção dos governantes e da sociedade civil pelo fato de reconhecerem a necessidade dessas ações. $O$ entendimento é de que esses "instrumentos podem facilitar a transparência e a responsabilização. Com isso [...] a institucionalização dessas atividades vem ganhando força" (BUENO e CARLOTO, 2015, p.15). Acredita-se que o protagonismo dos diferentes atores sociais no monitoramento e avaliação das políticas é condição indispensável para resultados mais efetivos.

\section{Políticas de Inclusão Social}

A Constituição Federal de 1988 apresenta, em seu artigo 5º o princípio da igualdade, no qual todas as pessoas devem receber tratamento igualitário perante a lei, sem distinção de qualquer natureza. O texto constitucional, a partir da sua promulgação, compromete-se com valores sociais imprescindíveis ao Estado Democrático de Direito. Questões como a defesa das minorias, o combate a pobreza e a superação de desigualdades historicamente arraigadas, tornam-se temas cruciais e que devem ser transpostos na visão desse projeto de nação.

Na primeira década do século XXI foram propostas soluções no tocante à "ampliação do acesso e maior equidade por intermédio da diversificação do sistema". Considerando esse cenário, o tema "Democratização do acesso à educação superior" revestiu-se de grande importância. A ampliação do ingresso a essa modalidade de ensino, bem como "a implantação das políticas de inclusão social resultaram em sua expansão" (NEVES et al., 2007, p. 124 - 125). Chama-se atenção para duas delas: a Política de Cotas e o PROUNI.

O Programa Universidade para Todos tem como finalidade a "concessão de bolsas de estudo integrais e parciais em cursos de graduação e sequenciais de formação específica" em instituições privadas de ensino superior. Os critérios adotados para ser contemplado pelo programa são voltados a estudantes egressos do ensino médio da rede pública ou da rede particular na condição de bolsistas integrais (BRASIL, 2017).

Tratando-se da Política de Cotas, Guarnieri e Melo-Silva (2017) comunicam que o primeiro programa de cotas no Brasil foi executado em 2003 pela Universidade Estadual do Rio de Janeiro (UERJ) e gradativamente adotado por outras universidades, vindo a se tornar Lei Federal no ano de 2012.

A Lei $\mathrm{n}^{0}$ 12.711/2012 dispõe sobre o ingresso nas universidades federais e nas instituições federais de ensino técnico de nível médio de uma significativa parcela da população advinda de camadas populares e de grupos que ao longo do processo histórico foram vítimas de preconceito por questões de raça e/ou etnia. As cotas são destinadas a $50 \%$ de alunos oriundos da escola pública, necessitando serem redistribuídas de acordo com critérios de renda e sobre um percentual de pretos, pardos e indígenas, conforme dados do censo demográfico do Instituto Brasileiro de Geografia e Estatística (IBGE) (BRASIL, 2012).

Não obstante aos avanços ocasionados por essas políticas, "o índice de oportunidades humanas ao acesso ao ensino superior no Brasil está muito longe da situação ideal que ocorre quando o acesso é universal e não há desigualdade de oportunidades no ingresso" (CARVALHO e WALTENBERG, 2015, p. 369). Nesse contexto e como superação das injustiças sociais e exclusão educacional, Souza (2003) reconhece a participação e articulação de outros segmentos e grupos de interesses, além dos governos, com as políticas públicas a fim de, conjuntamente, dirimirem essas mazelas sociais.

\section{Extensão Universitária}

A definição sobre Extensão Universitária vem sendo discutida e aprimorada ao longo do tempo. A partir de meados dos anos 80, início do processo de redemocratização do país, essa dimensão foi foco de intensos debates no meio acadêmico, na medida em que se buscava redimensionar a missão das universidades brasileiras direcionando-as para o compromisso e responsabilidade com a sociedade e com os segmentos menos favorecidos. Essa visão corroborava o pensamento de que discutir extensão é o mesmo que discutir a própria universidade (FORPROEX, 2013).

Partindo de uma concepção abordada por Paulo Freire, a extensão ou "comunicação", como 
defendia o educador, pode ser entendida como prática que envolve coparticipação dos sujeitos, a constituição de conhecimentos autênticos, ação e reflexão verdadeiras, promovendo transformação e conscientização (FREIRE, 1983). Santos (2004, p.54) em seu livro, A Universidade no Século XXI, enxerga nas atividades de extensão um meio para que a universidade tenha uma "participação ativa na construção da coesão social, no aprofundamento da democracia, na luta contra a exclusão social e a degradação ambiental e na defesa da diversidade cultural".

O Fórum Nacional de Pró-reitores de Extensão das Universidades Públicas Brasileiras (FORPROEX), concebido para coordenar a política de extensão, definiu essa dimensão como "um processo interdisciplinar, educativo, cultural, científico e político que promove a interação transformadora entre Universidade e outros setores da sociedade". Nesse sentido, esse processo educativo, sob o princípio constitucional da indissociabilidade entre ensino, pesquisa e extensão, permite que a universidade esteja sempre em sintonia com as demandas da população e que participe de forma ativa e interativa das mudanças sociais (FORPROEX, 2012, p.28).

Para consolidação da prática extensionista, foram estabelecidas, pela Política Nacional de Extensão, algumas diretrizes que devem orientar suas ações: Interação Dialógica, Interdisciplinaridade e Interprofissionalidade, Indissociabilidade Ensino-Pesquisa-Extensão, Impacto na Formação do Estudante, e Impacto e Transformação Social (FORPROEX, 2012).

A primeira dessas ações, por ordem de citação, refere-se à troca de saberes entre IFES e sociedade. Esse processo é visto como uma via de mão dupla que possibilita a construção do conhecimento por ambas as partes; a segunda pondera que, para intervir na complexa realidade social, é necessária a combinação de diferentes especializações; a terceira efetiva as ações de extensão na medida em que estão vinculadas ao ensino e a pesquisa; a quarta, por ampliar as referências na formação do estudante, enriquece seu aporte teórico e metodológico, permitindo a interação com grandes questões sociais; e a quinta reflete a inter-relação universidade e sociedade culminando em transformação social (FORPROEX, 2012).

Em conformidade com esse pensamento, Nogueira (2012) defende que a universidade deve estar "empenhada na busca de soluções para os problemas da maioria da população", por ser norteada pelo compromisso social. Nesse contexto, a extensão atuaria como instrumento para o cumprimento dessa função. Considera-se relevante, também, destacar a importância das potencialidades da extensão enquanto atividade produtora de conhecimento que melhora a capacidade técnica dos atores envolvidos tornando-os, assim, mais capazes de oferecer subsídios às políticas públicas (FORPROEX, 2012).

\section{Extensão Universitária e a participação nas Políticas Públicas}

Em maio de 2012, consolidou-se, no âmbito das discussões sobre Extensão Universitária do FORPROEX, o documento intitulado Política Nacional de Extensão Universitária. A partir de então, foram estabelecidas diretrizes para se promover maior unidade aos programas, projetos, cursos, eventos, prestações de serviço e elaboração e difusão de publicações e outros produtos acadêmicos de extensão.

Com a divulgação da política, reafirmou-se, entre seus objetivos, a necessidade de criar condições para que a Universidade tivesse participação primordial na elaboração, acompanhamento e avaliação das políticas públicas (FORPROEX, 2012). Para refletir sobre a correlação entre políticas públicas e extensão universitária, torna-se importante perceber o seu alcance que vai muito além do envolvimento com as ações específicas das instituições de ensino superior, difundindo-se com outras políticas públicas e setores do governo (Oliveira e Rocha, 2010, p. 9).

Diante desse escopo, e sob pactuação definida no âmbito FORPROEX, a Política Nacional de Extensão estabeleceu as áreas de atuação da extensão universitária em sua articulação com as políticas públicas orientadas por três eixos integradores, quais sejam:

a) Áreas temáticas (grandes focos de política social) - comunicação, cultura, direitos humanos e justiça, educação, meio ambiente, saúde, tecnologia e produção, trabalho;

b) Território - promoção da integração entre as políticas públicas e as ações extensionistas cujas diretrizes de interdisciplinaridade e interprofissionalidade promovam uma mudança nos efeitos próprios de determinados espaços que por si só constituem-se em representações sociais negativas;

c) Grupos populacionais - sujeitos populacionais específicos, especialmente em situação de vulnerabilidade social, reiterando o compromisso com o enfrentamento do combate a todas as formas de desigualdade e discriminação (FORPROEX, 2012). 
As ações de extensão universitária potencializam a formação acadêmica. "[...] Para a formação do profissional cidadão, é imprescindível sua efetiva interação com a sociedade, seja para se situar historicamente, para se identificar culturalmente e/ou para referenciar sua formação técnica com os problemas que um dia terá que enfrentar" (NOGUEIRA, 2000), ao passo que cria uma atmosfera para validar o compromisso social da universidade pública, capaz de oferecer subsídios aos governos na elaboração das políticas públicas.

A esse respeito, Pereira (2013) salienta a necessidade de compartilhamento dos setores sociais, privado e público, para governar, administrar, dirigir e orientar as ações das políticas públicas como princípio para o desenvolvimento social, de modo que privar as Universidades desse contexto é retroceder na função social que caracteriza a sua existência.

Nessa mesma linha de concepção, o Ministério de Educação (MEC), em parcerias com diversos órgãos federais, criou, em 2003, o Programa de Extensão Universitária (ProExt) com objetivo de apoiar as instituições públicas de ensino superior no desenvolvimento de programas ou projetos de extensão que contribuam para a implementação de políticas públicas.

Dentre as condições para participação do ProExt/MEC, é exigência tácita que as propostas apresentem programas ou projetos afins com as atuais temáticas de políticas públicas, em especial com as políticas sociais, e envolvam os estudantes de graduação regularmente matriculados na instituição (BRASIL, 2016b), tal condição corrobora o protagonismo do saber e fazer universitário, provocados pela extensão mediante a interação dialógica entre universidade e sociedade, na formulação, implementação e acompanhamento das políticas públicas prioritárias ao desenvolvimento regional e nacional.

A política de financiamento deste tipo de programa realiza-se por intermédio da concessão de recursos na Ação Orçamentária 20GK - Fomento às ações de Ensino, Pesquisa e Extensão da Lei Orçamentária Anual-LOA das Instituições de Ensino Superior-IES da esfera federal (BRASIL, 2016a). O desafio que se apresenta para esse modus operandi da extensão universitária, enquanto articuladora junto das políticas públicas, está em assegurar fontes estáveis para seu financiamento, de modo que sustentabilidade financeira e a continuidade das ações a elas vinculadas sejam garantidas.

É nesse âmbito que se fortalece a participação das universidades públicas nas ações governamentais com ênfase na inclusão social. Como destaca Pereira (2013): “o incentivo dado pelas universidades motiva uma maior interação com as camadas mais pobres da sociedade. [...] a descentralização das políticas públicas é o caminho mais adequado para o enfrentamento dos graves e complexos problemas dos países".

A responsabilidade social das universidades torna-se instrumento fundamental na construção da participação, por meio do conhecimento que produz, na gestão das políticas públicas, desafio precípuo a ser enfrentado na busca de melhor eficiência, eficácia e efetividade nos processos de concepção, implantação e avaliação das ações e programas desenvolvidos pelo Estado.

\section{Metodologia}

A pesquisa é de natureza qualitativa quanto ao método e à forma de abordar o problema. Esse tipo de pesquisa, em princípio, é caracterizada pela "não utilização de instrumental estatístico na análise dos dados" (ZANELLA, 2009, p.75). Quanto aos objetivos, é explicativa. De acordo com Vergara (2009, p. 42), "A investigação explicativa tem como principal objetivo tornar algo inteligível, justificarlhes os motivos. Visa, portanto, esclarecer quais fatores contribuem, de alguma forma, para a ocorrência de determinado fenômeno".

Considerando os meios de verificação, trata-se de pesquisa, ao mesmo tempo, estudo de caso, bibliográfica e documental. Conforme Vergara (2009, pp. 43 e 44), "estudo de caso é o circunscrito a uma pessoa ou poucas unidades, entendidas essas como pessoa, família, produto, empresa, órgão público, comunidade ou mesmo país". É utilizado quando se quer investigar uma questão do tipo "como" e por que" (YIN, 2007).

É bibliográfica porque para fundamentação teórica foi constituída investigação sobre os seguintes assuntos: Políticas Públicas; Política de Inclusão Social; Extensão Universitária; Extensão Universitária e a participação nas Políticas Públicas. Temas fundamentais para o desenvolvimento da pesquisa. Zanella (2009) afirma, a título de exemplo, que essa modalidade se apoia a partir do conhecimento disponível em livros e artigos. 
A análise feita na seção "resultados e discussão", no intuito de responder a questão inicial, efetivouse por meio do enquadramento do Pré-Enem Comunitário aos três eixos da Política Nacional de Extensão Universitária, necessários para que a articulação da extensão com as políticas públicas seja validada, são eles: Áreas Temáticas; Território e Grupos Populacionais. Concomitantemente realizou-se correlações entre objetivos e finalidades do Projeto com as políticas em questão.

No procedimento da análise documental foram utilizados dados da Universidade Federal de Alagoas, fornecidos via Serviço de Informação ao Cidadão. A solicitação foi protocolada pelo e-SIC, Processo $n^{\circ}$ 23065.036255/2017-16. O pedido contém elementos a respeito do Pré-Enem Comunitário. As informações abarcam o período de 2012 a 2016. O recorte atende aos objetivos da pesquisa. O ano de 2016 justifica-se ao se considerar os resultados da última seleção do Sistema de Seleção Unificada (SISU).

Além disso, a pesquisa usou dados colhidos no site da Instituição, como Relatórios de Gestão 2012 a 2016; Editais referentes ao Projeto. Também foram realizadas consultas ao Sistema Integrado de Gestão de Atividades Acadêmicas (SIGAA/Módulo Extensão), sítio eletrônico onde são cadastradas as ações de extensão.

\section{Resultados e Discussão}

Os resultados são apresentados em dois momentos: (1) inicialmente são trazidos os dados referentes ao histórico do Projeto, sua estrutura e alguns números relacionados. (2) Na segunda parte é feita a análise da articulação do Pré-Enem com as Políticas de Inclusão Social, em especial a Política de Cotas e o PROUNI.

\section{Pré-Enem Comunitário}

O Projeto Pré-Enem Comunitário, a princípio denominado Pré-Vestibular Comunitário, nasceu no âmbito do Programa Conexões de Saberes, este formulado e financiado pela Secretaria de Educação Continuada, Alfabetização, Diversidade e Inclusão (Secadi) do Ministério da Educação (MEC). Como referência para elaboração dessa ação, O MEC se baseou na Rede de Universitários de Espaços Populares (RUEP), programa desenvolvido pelo Observatório de Favelas do Rio de Janeiro, uma Organização da Sociedade Civil de Interesse Público (OSCIP) que atua como tal, desde 2003 (UFAL, 2012; OBSERVATÓRIO DE FAVELAS, 2013).

O Programa foi implementado na Universidade Federal de Alagoas no ano de 2006, por intermédio da Pró-reitoria de Extensão. A princípio era composto por quatro projetos: Pré-Vestibular Comunitário; Vizinhança; Educação Complementar e Cidadania; e Organização e Mobilização Universitária. Essa ação, que inicialmente recebia recursos do MEC, passou a ser custeada apenas pela UFAL, mediante pagamento de bolsas. O apoio financeiro do governo federal se ateve ao período de 2006 a 2011 (UFAL, 2015).

Em consequência a essas mudanças, houve uma adequação metodológica no programa. Devido à realidade financeira "as atividades se concentraram no espaço físico da UFAL, evitando deslocamentos de bolsistas até as comunidades". Além disso, buscou-se parcerias institucionais para melhoramento e alcance dos objetivos almejados (UFAL, 2015).

Desde 2013, o programa conta apenas com o Projeto Pré-Enem Comunitário, que tem como finalidade a "inserção de estudantes de escolas Públicas nas IFES, por meio de preparatórios até a realização do Exame Nacional do Ensino Médio (ENEM)". Em sua equipe de trabalho reúne professores, técnicos e estudantes da própria instituição, estes atuam como monitores nas aulas ministradas para os discentes inseridos no projeto (UFAL, 2013a).

Ao longo dos anos, os resultados das seleções para ingresso ao projeto têm alcançado uma quantidade significativa de estudantes, que ao estarem de acordo com os critérios iniciais, fazem uma prova objetiva nas mesmas áreas abordadas pelo Enem, estas áreas compõem o rol de disciplinas da "grade curricular" do curso. A Figura 1 apresenta o número de atendidos pelo Pré-Enem no período de 2012 a 2016.

Uma breve verificação desses dados remete a algumas informações citadas em parágrafos anteriores e que, de alguma forma, explicam a diferença entre o quantitativo de participantes de 2012 e dos anos subsequentes, foram elas: o corte de subsídio do governo federal e a realidade financeira vivenciada 
pelas IFES nos últimos anos. Questões como essas colocam em destaque a temática do financiamento, considerada crucial para realização das ações, porém não retiram a importância do projeto, pelo contrário, reforçam a necessidade de seu fortalecimento

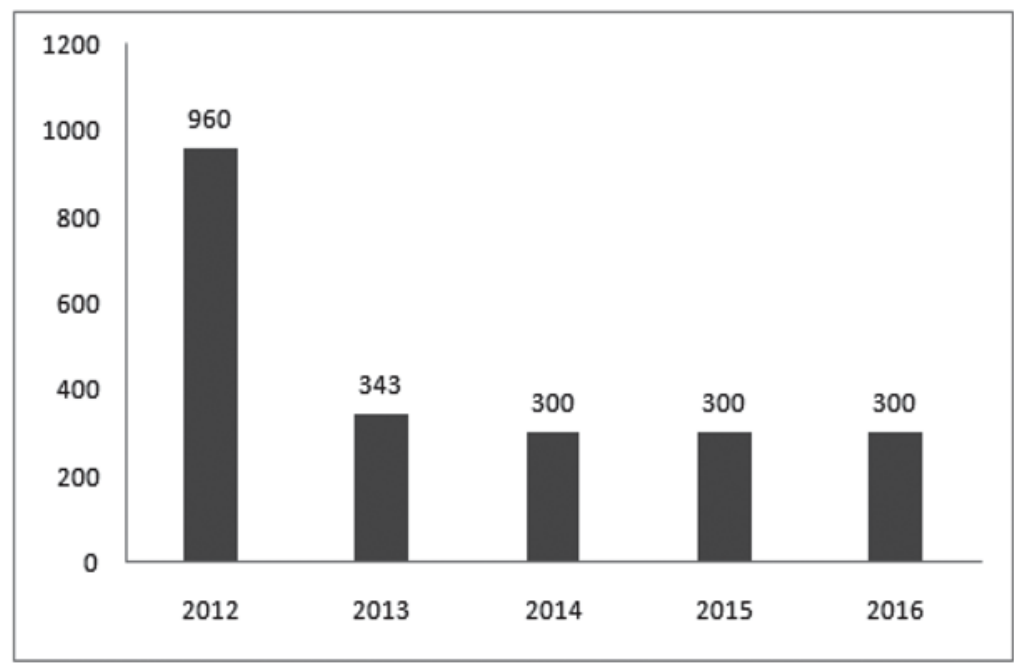

Figura 1 - Gráfico do Quantitativo de alunos matriculados no Pré-Enem por ano (período 2012 a 2016) Fonte:Elaborado pelos autores. Dados da UFAL obtidos pelo Serviço de Atendimento ao Cidadão - e-SIC, 2017a.

Por esse motivo, e como resposta a questão inicial deste artigo, será analisado, a seguir, o apoio do Pré-Enem Comunitário às Políticas Públicas de Inclusão Social, em particular a Política de Cotas e PROUNI, por intermédio do enquadramento do projeto aos eixos integradores necessários para que a articulação seja validada, consoante com o recomendado na Política Nacional de Extensão Universitária, ao mesmo tempo que serão feitas correlações demonstrando a convergência de objetivos e finalidades da ação extensionista e as políticas destacadas.

\section{Eixo Áreas Temáticas}

O Projeto se insere na área temática Educação. Segundo a Política de Extensão, essa classificação, por tema, tem correspondência com o objetivo da ação. Sendo assim e ciente de que a educação está relacionada a processos que visam o desenvolvimento da pessoa humana, o Pré-Enem, nessa mesma linha de entendimento, objetiva contribuir com as demandas fundamentais da população, marcada pelas desigualdades, por meio da construção de conhecimentos. É mediante essa inter-relação que se propõe a "valorizar expectativas e experiências de jovens de origem popular" auxiliando-os no ingresso a educação superior (UFAL, 2017b).

Esses aspectos dialogam com os intentos das Políticas destacadas, que também estão voltadas para área educacional, e objetivam corrigir injustiças sociais sofridas por parte de segmentos historicamente segregados pertencentes, em sua maioria, às camadas pobres. Essa convergência, entre objetivos de uma ação de extensão e uma política que se insere socialmente em atendimento aos problemas apresentados, possibilita a construção de espaços comuns de trocas de saberes e fazeres entre Universidade e Sociedade.

\section{Eixo Território}

Como salientado anteriormente, o território é o espaço onde a realidade social se mostra. As más condições de vida do lugar podem se constituir em uma matriz de reprodução das desigualdades e da exclusão. A integração entre extensão e políticas públicas surge como "estratégia excelente para contraarrestar esses efeitos negativos do território".

Sobre a mitigação de "efeitos negativos" de territórios marcados pelas desigualdades sociais, defende-se que o projeto contribui com esse "aliviamento", visto que em sua atuação têm atendido estudantes oriundos de comunidades populares, comumente, marcadas pela falta de acesso a direitos 
constitucionalmente garantidos, contribuindo, assim, com a formação de pessoas, que, possivelmente, não teriam acesso ao espaço de aprendizagem e construção de conhecimentos que as aulas proporcionam. É no sentido de redução dessas desigualdades que o projeto e as políticas em questão convergem.

O projeto alcança os espaços nos quais as realidades se mostram adversas. E faz isso por meio da formação oferecida aos discentes e da possibilidade de acesso à educação superior oportunizadas a eles. A respeito da "intervenção" do projeto nesses territórios, apresenta-se como exemplos as Figuras 2 e 3.

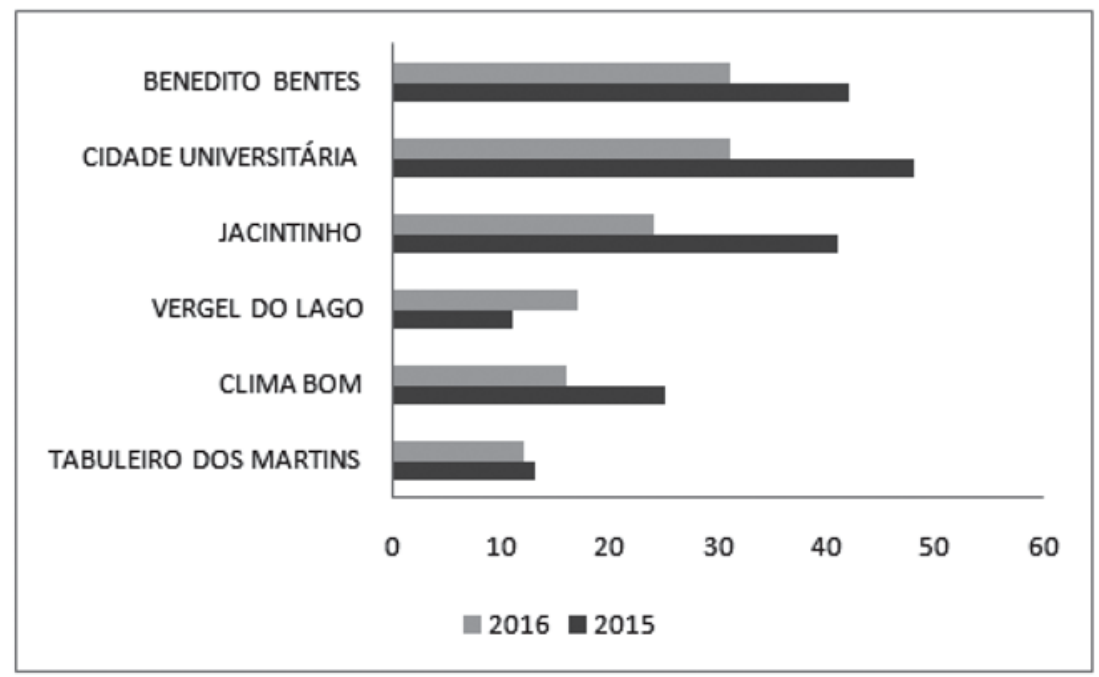

Figura 2 - Gráfico do Ranking dos seis bairros mais violentos de Maceió por número de homicídios, considerando os 6+ (seis mais) (Anos 2015 e 2016)

Fonte: Adaptado pelos autores. Dados da Secretaria de Estado da Segurança Pública de Alagoas obtidos pelo Site Agência Alagoas, 2016.

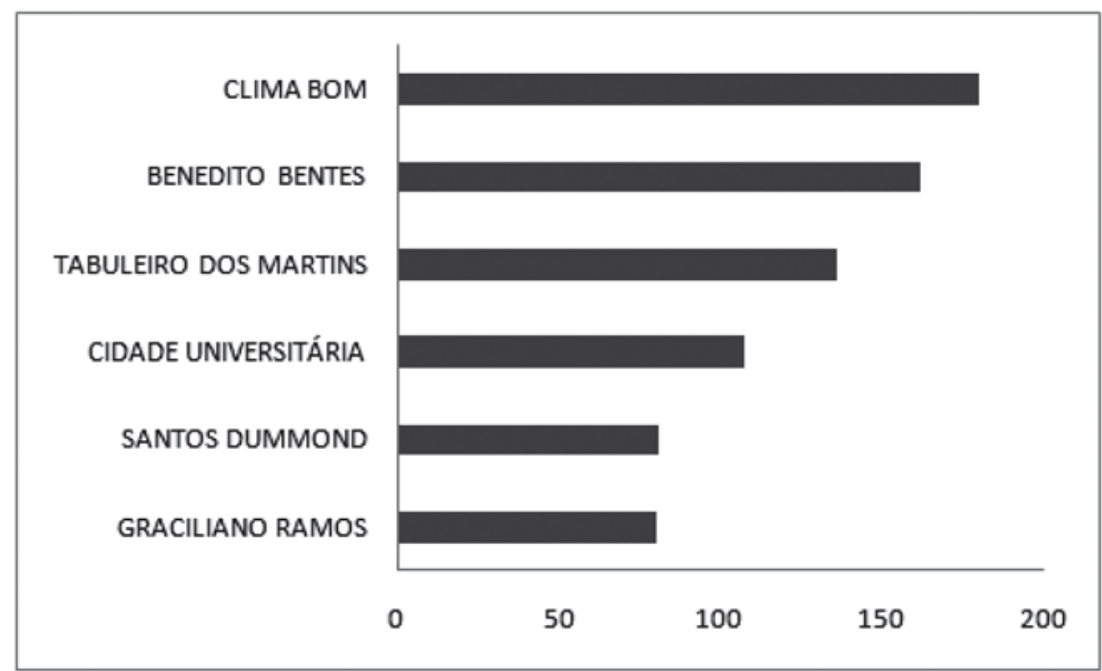

Figura 3 - Gráfico do Ranking dos bairros atendidos por números de alunos matriculados no PréEnem, considerando os 6 + (seis mais) (período 2012 a 2016).

Fonte: Elaborado pelos autores. Dados da UFAL obtidos pelo Serviço de Atendimento ao Cidadão - e-SIC, 2017a.

Estabelecendo uma correspondência entre as Figuras 2 e 3, é possível verificar que no Ranking dos 6+ (seis mais) bairros violentos de Maceió, quatro deles estão na listagem dos bairros com maior participação no Pré-Enem. Demonstrando que a ação se faz presente nesses territórios. Os dois outros bairros que aparecem no Ranking da violência também estão na listagem dos alcançados pelo projeto, apesar de não estarem nas seis primeiras colocações. Nos últimos cinco anos, a ação atendeu aproximadamente 51 bairros da capital alagoana e 37 municípios do Estado (UFAL, 2017a). 
Tendo em vista a diretriz da interdisciplinaridade e interprofissionalidade que deve orientar as intervenções extensionistas nos espaços de atuação, o projeto conta com o apoio de profissionais e alunos de diferentes formações. Ademais, se associou ao Programa de Apoio às Escolas Públicas (PAESP) ação de extensão de grande relevância, bem como mantém parcerias com outras instituições, entre elas: a Secretaria de Estado de Ressocialização e Inclusão Social (SERIS), com a finalidade de revisão para o ENEM/PPL em suporte aos reeducandos do Sistema Prisional Alagoano. Somadas a essas ações, o projeto promove aulões, por área de conhecimento, e simulados, contemplando um número de pessoas maior do que as atendidos, habitualmente. (UFAL, 2016a).

\section{Eixo Grupos Populacionais}

Nesse eixo, a integração entre as ações de extensão junto às políticas públicas se direciona a populações específicas, em especial aos excluídos e em vulnerabilidade social. Seguindo essa mesma orientação, o Pré-Enem adota critérios de inserção que contemplam grupos populacionais caracterizados pela falta de oportunidades, fruto das desigualdades sociais. No Quadro 1, é possível ver a semelhança entre os públicos-alvo do projeto e das políticas evidenciadas neste estudo.

Quadro 1 - Critérios definidores dos Públicos-alvo da Política de Cotas, do PROUNI e do Pré-Enem

\begin{tabular}{|c|c|}
\hline Política/Ação & Critérios /Público Alvo \\
\hline $\begin{array}{l}\text { Cotas para } \\
\text { Universidades e } \\
\text { Institutos Federais } \\
\text { Lei } 12.711 / 2012\end{array}$ & $\begin{array}{l}\text { Estudantes de escolas públicas com renda familiar bruta igual } \\
\text { ou inferior a um salário mínimo e meio per capita e metade para } \\
\text { estudantes de escolas públicas com renda familiar superior a um } \\
\text { salário mínimo e meio. }\end{array}$ \\
\hline PROUNI & $\begin{array}{l}\text { Estudantes egressos do ensino médio da rede pública ou da rede } \\
\text { particular na condição de bolsistas integrais. Bolsa integral para } \\
\text { os que possuam renda familiar, per capita, de até um salário } \\
\text { mínimo e meio. Bolsa parcial de } 50 \% \text { para aqueles que possuam } \\
\text { renda familiar, per capita, de até três salários mínimos. }\end{array}$ \\
\hline $\begin{array}{l}\text { Pré-Enem } \\
\text { Comunitário/UFAL }\end{array}$ & $\begin{array}{l}\text { Estudantes oriundos de escolas públicas, que estão cursando o } \\
3^{\circ} \text { ano do ensino médio, além de terem cursado o } 1^{\circ} \text { e } 2^{\circ} \text { ano em } \\
\text { escola pública ou da rede particular na condição de bolsista } \\
\text { integral com renda per capita familiar igual ou inferior a } 1,5 \text { (um } \\
\text { e meio) salários mínimos vigente. }\end{array}$ \\
\hline
\end{tabular}

Fonte: Elaborado pelos autores. Dados da UFAL, 2016b e BRASIL, 2017.

A partir da adoção desses critérios, o projeto tem contribuído com a formação e com o acesso desses grupos populacionais ao ensino superior, como demonstra a Figura 4.

No ano de 2012, conforme visto, o projeto atendia um quantitativo maior de pessoas, supõe-se que isso explique a diferença entre os ingressantes desse ano e os subsequentes. Os resultados quanto ao número de alunos que entraram nas universidades públicas e em IFES particulares, via PROUNI, são informados pelos próprios alunos e colhidos em bancos de dados da UFAL (UFAL, 2017a). Assim sendo, considera-se importante a necessidade de mecanismos de acompanhamento a fim de ter informações mais precisas, tendo em vista que alguns alunos podem não entrar em contato com a equipe do projeto.

Considerando a análise realizada, por meio do enquadramento do Pré-Enem aos três eixos necessários à articulação com as Políticas Públicas, verificou-se que a ação cumpre com as orientações da Política Nacional de Extensão, visto que contempla em seu escopo e atuação os aspectos dos eixos integradores. Da mesma forma, confirmou-se seu apoio, indireto, a Política de Cotas e ao PROUNI, pelo fato dos critérios de acesso e a finalidade do projeto convergirem para os adotados por essas políticas, visando, igualmente, o acesso a educação superior por segmentos da população marcados pela desigualdade econômica e social. É nesse sentido que se defende haver a articulação. 


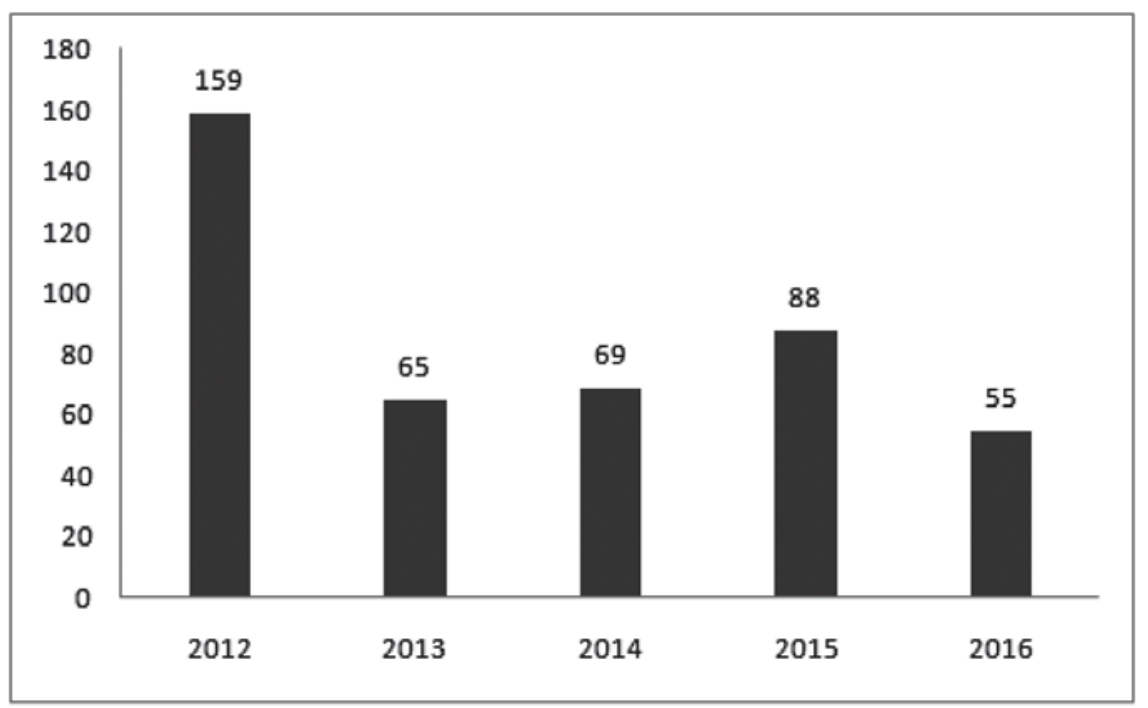

Figura 4 - Gráfico do Quantitativo de alunos do Pré-Enem que ingressaram em universidade pública e/ou em instituições de ensino superior privadas por intermédio do PROUNI (período 2012 a 2016).

Fonte: Elaborado pelos autores. Dados da UFAL obtidos pelo Serviço de Atendimento ao Cidadão - e-SIC, 2017a.

\section{Considerações Finais}

O artigo buscou analisar a articulação do projeto Pré-Enem Comunitário da Universidade Federal de Alagoas com as Políticas Públicas de Inclusão Social, em particular a Política de Cotas e o PROUNI. Para tanto, se fundamentou em conceitos necessários ao desenvolvimento da pesquisa e em eixos integradores, pactuados no âmbito do FORPROEX, que serviram de base para realização das discussões e resultados obtidos.

Corroborando com essas discussões, apreende-se que compreender a importância da extensão articulada às políticas públicas perpassa, primeiramente, pelo entendimento da responsabilidade social das IFES, do seu comprometimento com as questões e problemas enfrentados pela população bem como seu protagonismo nos debates e soluções para essas demandas, sem, contudo, eximir os governos de suas obrigações na efetivação de direitos sociais.

Entende-se que a análise realizada contribui para visibilidade e a importância das ações de extensão. Como visto, elas podem apresentar dificuldades de ordem financeira, como as vivenciadas pelo projeto. Contudo, um olhar mais aprofundado sobre suas atuações demonstra o quanto são relevantes à sociedade e necessitam de subsídios, a fim de alcançarem resultados cada vez mais expressivos, contribuindo, dessa forma, para amenização das desigualdades.

Conforme discutido, apesar do projeto não se articular de forma direta com as políticas destacadas no artigo, na medida em que não participou da formulação e implementação delas, ele as auxilia de forma indireta, pela intencionalidade em definir critérios de acesso semelhantes e direcioná-los a grupos populacionais que vivenciam em seu cotidiano situações socialmente adversas.

Entretanto, considerando o processo formativo do Pré-Enem, pode-se supor que ele oferece um diferencial competitivo aos participantes que, provavelmente, não teriam caso não tivessem ingressado no projeto. Tal diferencial advém do seguinte fato: durante o período de um ano os discentes apreendem conhecimentos relacionados aos conteúdos abordados pelo Exame Nacional do Ensino Médio. Como consequência disso, alguns podem adentrar às IFES públicas sem a utilização das cotas. Essa questão pode vir a ser pesquisada, caso haja um acompanhamento mais sistemático das pessoas atendidas pela ação.

Como assinalado no início dessa seção, o artigo se limitou a analisar a articulação entre extensão e políticas públicas utilizando um único caso: o Projeto Pré-Enem. Pela importância do cumprimento das diretrizes das ações de extensão, pactuadas mediante diálogos entre os diversos atores, pelo fortalecimento da extensão e, por entender que esta se constitui em elo viabilizador da relação entre IFES e sociedade é que se sugere a ampliação da presente pesquisa, no sentido de analisar se, na prática, a Política de Extensão Institucional, por meio de seus projetos e programas, tem levado em conta a articulação com as políticas públicas governamentais. 


\section{Referências}

ALAGOAS. Agência Alagoas. Bairros considerados violentos em Maceió registram redução no número de homicídios.2016. Disponível em:< http://www.agenciaalagoas.al.gov.br/noticia/item/6300-bairros-considerados-violentos-em-maceio-registram-reducao-no-numero-de-homicidios> Acesso em 15 de dezembro de 2017.

ARRETCHE, Marta. Dossiê agenda de pesquisas em políticas públicas. Revista Brasileira de Ciências Sociais. 2003, vol.18, n.51, pp.7-10. ISSN 1806-9053. Disponível em:<http://dx.doi.org/10.1590/ S0102-69092003000100001> Acesso em 15 de dezembro de 2017.

BRASIL. Lei $\mathrm{n}^{\mathrm{o}} 12.711$, de29 de agosto de 2012. Dispõe sobre o ingresso nas universidades federais e nas instituições federais de ensino técnico de nível médio e dá outras providências. Brasília, DF, ago. 2012. Disponível em:< http://www.planalto.gov.br/ccivil_03/_ato2011-2014/2012/lei/ 112711.htm>Acesso em 15 de dezembro de 2017.

Câmara dos Deputados. Consultoria de Orçamento e Fiscalização Financeira. Nota técnica $n^{\circ} 1 / 2016$. Brasília, 2016a. Disponível em:< http://www2.camara.leg.br/orcamento-da-uniao/ estudos/2016/nt01_2016>Acesso em 6 de janeiro de 2018.

Ministério da Educação. EDITAL PROEXT 2016 PROGRAMA DE APOIO À EXTENSÃO UNIVERSITÁRIA MEC/SESu. 2016B. Disponível em : <http://portal.mec.gov.br/ index.php?option $=$ com_docman\&view $=$ download \&alias $=17188-$ proext $-01-2016$ edital\&category_slug=marco-2015-pdf\&Itemid=30192>.Acessoem : 6 de janeiro de 2018.

Portal do Ministério da Educação. Perguntas Frequentes. Disponível em:< http:// portal.mec.gov.br/cotas/perguntas-frequentes.html> Acesso em 15 de dezembro de 2017.

Ministério da Educação. Programa Universidade para Todos. Disponível em:< http:// prouniportal.mec.gov.br/o-programa> Acesso em 16 de dezembro de 2017.

BUENO, Nayara Cristina; CARLOTO, Cássia Maria. Avaliação e monitoramento da política de assistência social: uma proposta em construção.Rev. katálysis, Florianópolis , v. 18, n. 1, p. 13-21, June 2015 . Disponível em:<http://www.scielo.br/scielo.php?script=sci_arttext\&pid= S141449802015000100013\&lng=en\&nrm=iso>. Acesso em:6 Jan. 2018.

CAPELLA, A C. N. Perspectivas teóricas sobre o processo de formulação de políticas públicas.BIB, Revista Brasileira de Informação Bibliográfica em Ciências Sociais, v. 61, 2006. Disponível em:<https:/ /pt.slideshare.net/Petianos/ perspectivas-tericas-sobre-o-processo-de-formulao-de-polticaspblicas>Acesso em 6 Jan. 2018.

CARVALHO, Márcia Marques de; WALTENBERG, Fábio d. Desigualdade de oportunidades no acesso ao ensino superior no brasil: uma comparação entre 2003 e 2013.Econ. Apl., Ribeirão Preto , v. 19, n. 2, p. 369-396, June 2015 . Disponível em:<http://www.scielo.br/ scielo.php?script=sci_arttext\&pid=S141380502015000200369\&lng=en\&nrm=iso $>$.Acesso em: 10 Jan. 2018. http://dx.doi.org/10.1590/1413-8050/ea124777.

DALFIOR, Eduardo Tonole; LIMA, Rita de Cássia Duarte; ANDRADE, Maria Angélica Carvalho. Implementação de políticas públicas: metodologia de análise sob o enfoque da política institucional.Saúde debate, Rio de Janeiro, v. 39, n. spe, p. 283-297, Dec.2015 . Disponível em:<http:/

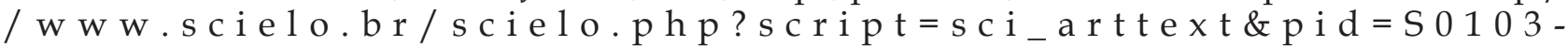
$11042015000500283 \& \operatorname{lng}=\mathrm{en} \& \mathrm{nrm}=\mathrm{iso}>$.Acesso em: 8 Jan. $201 \overline{8}$.

FORPROEX. Comissão permanente de Avaliação. Avaliação da Extensão Universitária: práticas e discussões da Comissão Permanente de Avaliação da Extensão. Org. Maria das Dores Pimentel Nogueira; textos: Sonia Regina Mendes dos Santos... [et al.] - Belo Horizonte: FORPROEX/CPAE; PROEX/UFMG, 2013.

FORPROEX. Política Nacional de Extensão Universitária. Manaus, 2012.

FÓRUM DE PRÓ-REITORES DE EXTENSÃO DAS INSTITUIÇÕES PÚBLICAS DE EDUCAÇÃO SUPERIOR BRASILEIRAS (FORPROEX). Política Nacional de Extensão Universitária. Gráfica da UFRGS. Porto Alegre, RS, 2012 (Coleção Extensão Universitária; v. 7). 
FREIRE, Paulo. Extensão ou comunicação? 7a ed. Rio de Janeiro, Paz e Terra, 1983.

GADOTTI, Moacir. Extensão Universitária: Para quê? Instituto Paulo Freire,2017. Disponívelem <https:/ / www.paulofreire.org/images/pdfs/Extens\%C3\% A3o_Universit\%C3\% A1ria__Moacir_Gadotti_fevereiro_2017.pdf> Acesso em 15 de dezembro de 2017.

GONÇALVES, Nadia Gaiofatto. Indissociabilidade entre Ensino, Pesquisa e Extensão: um princípio necessário.Perspectiva, Florianópolis, v. 33, n. 3, p. 1229-1256, abr. 2016. ISSN 2175-795X.Disponível em:https:/ / periodicos.ufsc.br/index.php/perspectiva/article/view/2175-795X.2015v33n3p1229> Acesso em:31 dez. 2017.

GUARNIERI, Fernanda Vieira and MELO-SILVA, Lucy Leal. Cuotas universitarias en Brasil: análisis de una década de producción científica. Psicol. Esc. Educ. [online]. 2017, vol.21, n.2, pp.183-193.

INSTITUTO DE PESQUISA ECONÔMICA APLICADA. Aumenta a interação do Estado com a sociedade. 2012.Disponível em:<http://www.ipea.gov.br/portal/index.php?option=com_content\&view= article\&id=12994\&Itemid=1> Acesso em 19 de dezembro de 2017.

LIMA, Luciana Leite; D’ASCENZI, Luciano. Estrutura normativa e implementação de políticas públicas. In Avaliação de políticas públicas. Porto Alegre : UFRGS, 2014. p. 50-63. Disponível em:<http:/ /www.lume.ufrgs.br/handle/10183/108186>Acesso em 19 de dezembro de 2017.

LIMA, Luciana Leite; D’ASCENZI, Luciano. Implementação de políticas públicas: perspectivas analíticas.Rev. Sociol. Polit.[online]. 2013, vol.21, n.48, pp.101-110.

NEVES, Clarissa Eckert Baeta; RAIZER, Leandro; FACHINETTO, Rochele Felline. Acesso, expansão e eqüidade na educação superior : novos desafios para a política educacional brasileira. In Sociologias. Porto Alegre. Vol. 9, n. 17 (jan./jun. 2007), p. 124-157.

NOGUEIRA, Maria das Dores Pimentel. Curso de Formação em Avaliação da Extensão Universitária.2012. Disponível em: http://www.utfpr.edu.br/estrutura-universitaria/pro-reitorias/prorec/diretoriade-extensao/fale-conosco/apresentacao-da-maria-das-dores-nogueira Acesso em 20 de dezembro de 2017.

OBSERVATÓRIO DE FAVELAS. Conexões de Saberes. 2013. Disponível em:<http://of.org.br/ apresentacao/>Acesso em 20 de dezembro de 2017.

OLIVEIRA, Claudia Hochheim. Qual é o Papel da Extensão Universitária? Algumas Reflexões Acerca da Relação entre Universidade, Políticas Públicas e Sociedade. Anais do $2^{\circ}$ Congresso Brasileiro de Extensão Universitária, 2014.

OLIVEIRA, Carlos Eduardo C. de; ROCHA, Saulo José dos Santos. Estado, Políticas Públicas e Extensão Universitária. RDE-Revista de Desenvolvimento Econômico, 2010.

PEREIRA, Lucas Batista. Extensão Universitária e Políticas Públicas.Revista Extensão E Cidadania, 2013.

PETERS, Brainard Guy.American Public Policy. Chatham, N.J.: Chatham House. 1986.

RAMOS, Marilia Patta; LIMA, Luciana Leite. Avaliação de políticas sociais no Brasil: o caso do programa bolsa família. In Avaliação de políticas públicas. Porto Alegre: UFRGS, 2014. p. 64-82 Disponível em:< http://www.lume.ufrgs.br/handle/10183/108187> Acesso em 15 de dezembro de 2017.

SANTOS, Alfredo Balduíno. Extensão Universitária como viabilizadora de políticas públicas.2012.98.f. Dissertação (Mestrado em Gestão de Políticas Públicas), Universidade do Vale do Itajaí, Santa Catarina.

SANTOS, Boaventura Souza. A Universidade no século XXI: para uma reforma democrática e emancipatória da Universidade. São Paulo: Cortez, 2004.

SOUZA, Celina. Políticas Públicas: questões de temáticas e de pesquisa. 2003. In Cadernos CRH.Disponível em:<https://portalseer.ufba.br/index.php/crh/article/view/18743/12116>Acesso em 23 de dezembro de 2017. 
SOUZA, Celina. Políticas públicas:uma revisão da literatura. Sociologias[online]. 2006, n.16, pp.20-45. ISSN 1517-4522

UFAL. Pró-reitoria de Extensão. Relatório de Gestão. 2012. Disponível em: <http://www.ufal.edu.br/ extensao/documentos/relatorios/gestao/2012/view> Acesso em: 2 de janeiro de 2018.

UFAL. Pró-reitoria de Extensão. Relatório de Gestão. 2012. Disponível em: <http://www.ufal.edu.br/ extensao/documentos/relatorios/gestao/2012/view> Acesso em: 2 de janeiro de 2018.

Pró-reitoria de Extensão. Relatório de Gestão.2013a. Disponível em: <http:// www.ufal.edu.br/extensao/documentos/relatorios/gestao/2013/view> Acesso em: 2 de janeiro de 2018.

Plano de Desenvolvimento Institucional. 2013b. Disponível em: <http:/ /www.ufal.edu.br/ transparencia/institucional/plano-de-desenvolvimento/2013-2017/view> Acesso em 10 de janeiro de 2018.

Pró-reitoria de Extensão. Relatório de Gestão. 2014. Disponível em: <http:// www.ufal.edu.br/extensao/documentos/relatorios/gestao/2014/view> Acesso em: 2 de janeiro de 2018.

Pró-reitoria de Extensão. Relatório de Gestão. 2015. Disponível em: <http:// www.ufal.edu.br/extensao/documentos/relatorios/gestao/2015/view> Acesso em: 2 de janeiro de 2018.

Pró-reitoria de Extensão. Relatório de Gestão. 2016a. Disponível em: <http:// www.ufal.edu.br/extensao/documentos/relatorios/gestao/2016/view> Acesso em: 2 de janeiro de 2018.

Pró-reitoria de Extensão. Edital Pré-Enem. Programa Conexões de Saberes/Ufal. 2016b. Disponível em: <http://www.ufal.edu.br/utilidades/concursos-e-editais/extensao/selecao-do-curso-pre-enem-2014-programa-conexoes-de-saberes-ufal/edital-curso-pre-enem-2014-programaconexoes-de-saberes-ufal> Acesso em: 2 de janeiro de 2018.

Pró-reitoria de Extensão. Serviço de informação ao Cidadão. Processo $n^{0}$ 23065.036255/ 2017-16. 2017a. Disponível em: <http://www.ufal.edu.br/extensao/ documentos/relatorios/ gestao/2016/view> Acesso em: 2 de janeiro de 2018.

. Sistema Integrado de Gestão de Atividades Acadêmicas/SIGAA. Projeto Pré-Enem Comunitário. PJ078-2017. 2017b. Disponível em: <http://sigaa.sig.ufal.br/sigaa/ public/extensao/ consulta_extensao.jsf> Acesso em: 2 de janeiro de 2018.

VERGARA, Sylvia Constant. Projetos e relatórios de Pesquisa em administração. 11.ed. Rio de Janeiro: Atlas, 2009.

YIN, Robert K. Estudo de caso: planejamento e métodos. $3^{\text {a }}$ ed. Porto Alegre: Bookman, 2007.

ZANELLA, Liane Carly Hermes. Metodologia de estudo e de pesquisa em administração. Florianópolis: Departamento de Ciências da Administração/UFSC; [Brasília]: CAPES: UAB, 2009.

Recebido para publicação em 03/05/2018 e aprovado em 22/06/2018. 